\title{
Statistik Terapan: Pengujian Regulasi \& Kebijakan Telekomunikasi
}

Sigit Haryadi

Institut Teknologi Bandung

February 2018

Paper DOI: 10.17605/OSF.IO/6XJ7R

Haryadi, S. (2018, February 6). Statistik Terapan: Pengujian Regulasi \& Kebijakan

Telekomunikasi. Retrieved https://osf.io/preprints/inarxiv/6xj7r

\section{Ringkasan:}

Makalah ini berisi ilmu statistic terapan mengenai teknik menguji keberhasilan regulasi \& kebijakan, disertai contoh-contoh soal khususnya pada bidang telekomunikasi, di dalamnya terdapat metoda eksisting yang berupa uji perbedaan, uji asosiasi korelasional dan uji asosiasi kausalitas yang dibandingkan dengan metoda baru yang berkaitan dengan keadilan.

\section{Metoda Eksisting}

Untuk menilai apakah suatu regulasi atau kebijakan telekomunikasi telah berhasil atau tidak, pada metoda eksisting, biasa dilakukan suatu Uji Perbedaan yang diikuti dengan Uji Asosiasi.

\section{Uji Perbedaan:}

Adalah menguji perbedaan yang terjadi ketika suatu regulasi atau kebijakan telah dilaksanakan pada suatu time-lag tertentu, yang dibandingkan dengan kondisi ketika regulasi atau kebijakan baru dimulai implementasinya. Misalkan suatu regulasi atau kebijakan telekomunikasi mulai diberlakukan pada tanggal 1 Juli 2017, maka yang dibandingkan adalah kondisi sebelum 1 Juli 2017, misalkan dengan kondisi pada 1 Januari 2018, dimana dalam kasus ini time lag yang digunakan adalah 6 bulan, suatu periode yang paling minimum untuk digunakan.

\section{Uji Asosiasi:}

Uji asosiasi merupakan pelengkap dari uji perbedaan, yang harus dilakukan untuk lebih memperdalam analisis terhadap keberhasilan suatu regulasi atau kebijakan, dan terdiri dari dua jenis: 
1) Uji Asosiasi Kausalitas: pengujian terhadap variable - variabel sebelum vs sesudah kebijakan apakah mempunyai hubungan sebab akibat

2) Uji Asosiasi Korelasional: pengujian terhadap variabel-variabel sebelum vs sesudah kebijakan apakah mempunyai hubungan korelasional.

\subsection{Problem \& Solution 1: Perhitungan Asosiasi Korelasional}

Pada tahun 2004/2005, pemerintah atas desakan dari WTO, meliberalisasikan bisnis telekomunikasi di Indonesia, khususnya dengan cara mengakhiri era monopoli pemerintah, , sekaligus melepaskan sebagian saham negara dari operator - operator telekomunikasi eksisting yang sebelumnya masih $100 \%$ dikuasasi negara.

Pertama dilakukan uji perbedaan, terdapat fakta bahwa setelah kebijakan tersebut diimplementasikan, ternyata jumlah pelanggan telekomunikasi dan EBITDA rata-rata operator telekomunikasi di Indonesia selalu meningkat dari tahun ke tahun.

SOAL: Lakukan pengujian untuk mengetahui apakah keberhasilan regulasi liberalisasi tersebut telah memberi dampak positif bagi GDP negara kita, yaitu dengan melakukan UJI ASOSIASI KORELASIONAL antara variabel bertambahnya jumlah pelanggan dengan naiknya EBITDA dari para operator seluler.

\section{Jawab:}

Berdasar data di bawah, khusus pada soal ini, uji asosiasi korelasional yang paling sesuai adalah dengan menggunakan teknik uji korelasi peringkat Spearman $\left(\mathrm{r}_{\mathrm{s}}\right)$

Rumus uji korelasi Spearman adalah sebagai berikut

$$
r_{s}=1-\frac{6 \sum d_{i}^{2}}{n^{3}-n}
$$

Dimana:

- $\mathrm{d}_{\mathrm{i}}=$ selisih peringkat masing-masing metrik

- $\mathrm{n}=$ populasi data

Dari soal di atas:

- $\boldsymbol{H O}=$ Hipotesis nol (= negasi atau bantahan terhadap pernyataan yang akan dibuktikan) adalah: "bertambahnya jumlah pelanggan telekomunikasi TIDAK mempunyai hubungan korelasional positif terhadap naiknya EBITDA para operator telekomunikasi".

- Pengujian terhadap hipotesis nol dilakukan dengan membandingkan $r_{s}$ dengan tabel khusus nilai kritis yang mencakup nilai pada taraf signifikansi 0,0 sesuai soal. 
- Kriteria pengujian untuk korelasi positif: Tolak $\mathrm{H}_{0}$ jika $\mathrm{r}_{\mathrm{s}}>\mathrm{r}_{\text {tabel }}$ dan Terima $\mathrm{H}_{0}$ jika $\mathrm{r}_{\mathrm{s}} \leq \mathrm{r}_{\text {tabel }}$

- Kriteria pengujian untuk korelasi negatif : Tolak $\mathrm{H}_{0}$ jika $\mathrm{r}_{\mathrm{s}}<-\mathrm{r}_{\text {tabel }}$ dan Terima $\mathrm{H}_{0}$ jika $r_{s} \geq-r_{\text {tabel }}$

- Tabel Nilai Kritis dari Koefisien Korelasi Peringkat Spearman untuk tingkat signifikansi 0,01 adalah sebagai berikut: $\{$ ukuran sampel; $\alpha\}=\{5,6,7,8,9,10,12$, $14,16,18,20,22,24,26,28,30 ; 1,0.943,0.893,0.833,0.783,0.746,0.712,0.645$, $0.601,0.564,0.534,0.508,0.485,0.465,0.448,0.432\}$

\section{Data Yang diketahui:}

\begin{tabular}{|c|c|c|c|c|c|c|c|c|}
\hline \multirow{2}{*}{ Penyelenggara } & \multicolumn{2}{|l|}{ Tahun 2004} & \multicolumn{2}{|l|}{ Tahun 2005} & \multicolumn{2}{|l|}{ Tahun 2006} & \multicolumn{2}{|l|}{ Tahun 2007} \\
\hline & Pelanggan & EBITDA (M) & Pelanggan & EBITDA (M) & Pelanggan & EBITDA (M) & Pelanggan & EBITDA (M) \\
\hline Telkom & 9988718 & 21899 & 11934844 & 25660 & 12885064 & 31716 & 15048000 & 37067 \\
\hline Indosat & 9807379 & 6016 & 14783993 & 6732 & 17090341 & 7051 & 25203835 & 8715 \\
\hline Bakrie & 190961 & 1 & 372129 & 240 & 1547557 & 291 & 3820701 & 545 \\
\hline Mobile 8 & 500 & 1 & 1200000 & 12 & 1825868 & 239 & 3012801 & 397 \\
\hline Telkomsel & 16291000 & 10672 & 24269000 & 15408 & 35597000 & 20737 & 47910000 & 25604 \\
\hline $\mathrm{XL}$ & 3791000 & 1626 & 6978519 & 1735 & 9527970 & 2554 & 15469000 & 3509 \\
\hline Total & 40069558 & 40215 & 59538485 & 49787 & 78473800 & 62588 & 110464337 & 75837 \\
\hline
\end{tabular}

\section{Data diolah agar bisa menjawab soal:}

\begin{tabular}{|c|c|c|c|c|c|c|}
\hline \multirow[b]{2}{*}{ Penyelenggara } & \multicolumn{2}{|c|}{ Tahun 2004-2005 } & \multicolumn{2}{|c|}{ Tahun 2005-2006 } & \multicolumn{2}{|c|}{ Tahun 2006-2007 } \\
\hline & $\begin{array}{l}\% \\
\text { bertambah } \\
\text { Pelanggan }\end{array}$ & $\begin{array}{l}\text { \% naik } \\
\text { EBITDA (M) }\end{array}$ & $\begin{array}{l}\% \\
\text { bertambah } \\
\text { Pelanggan }\end{array}$ & $\begin{array}{l}\text { \% naik } \\
\text { EBITDA (M) }\end{array}$ & $\begin{array}{l}\% \\
\text { bertambah } \\
\text { Pelanggan }\end{array}$ & $\begin{array}{l}\text { \% naik } \\
\text { EBITDA (M) }\end{array}$ \\
\hline Telkom & 19,48 & 17,17 & 7,96 & 23,6 & 16,79 & 16,87 \\
\hline Indosat & 50,74 & 11,9 & 15,6 & 4,74 & 47,47 & 23,6 \\
\hline Bakrie & 94,87 & 23900 & 315,87 & 21,25 & 146,89 & 87,29 \\
\hline Mobile 8 & 239900 & 1100 & 52,16 & 1891,67 & 65,01 & 66,11 \\
\hline Telkomsel & 48,97 & 44,38 & 46,68 & 34,59 & 34,59 & 23,47 \\
\hline $\mathrm{XL}$ & 84,08 & 6,7 & 36,53 & 47,2 & 62,35 & 37,39 \\
\hline Total & 48,59 & 23,8 & 31,8 & 25,71 & 40,77 & 21,17 \\
\hline
\end{tabular}


Perhitungan nilai d kuadrat:

\begin{tabular}{|c|c|c|c|c|c|}
\hline $\begin{array}{l}\text { \% bertambah } \\
\text { Pelanggan }\end{array}$ & Peringkat & $\begin{array}{l}\% \text { naik } \\
\text { EBITDA }\end{array}$ & Peringkat & d & d kuadrat \\
\hline 19,48 & 15 & 17,17 & 14 & 1 & 1 \\
\hline 50,74 & 9 & 11,9 & 16 & -7 & 49 \\
\hline 94,87 & 4 & 23900 & 1 & 3 & 9 \\
\hline 239900 & 1 & 1100 & 3 & -2 & 4 \\
\hline 48,97 & 10 & 44,38 & 7 & 3 & 9 \\
\hline 84,08 & 3 & 6,7 & 12 & -9 & 81 \\
\hline 7,96 & 18 & 23,6 & 10 & 8 & 64 \\
\hline 15,6 & 17 & 4,74 & 18 & -1 & 1 \\
\hline 315,87 & 2 & 21,25 & 13 & -11 & 121 \\
\hline 52,16 & 8 & 1891,67 & 2 & 6 & 36 \\
\hline 46,68 & 12 & 34,59 & 9 & 3 & 9 \\
\hline 36,53 & 13 & 47,2 & 6 & 7 & 49 \\
\hline 16,79 & 16 & 16,87 & 15 & 1 & 1 \\
\hline 47,47 & 11 & 23,6 & 10 & 1 & 1 \\
\hline 146,89 & 3 & 87,29 & 4 & -1 & 1 \\
\hline 65,01 & 6 & 66,11 & 5 & 1 & 1 \\
\hline 34,59 & 14 & 23,47 & 12 & 2 & 4 \\
\hline \multirow[t]{2}{*}{62,35} & 7 & 37,39 & 8 & -1 & 1 \\
\hline & & & & Jumlah= & 442 \\
\hline
\end{tabular}

Perhitungan koefisien korelasi Spearman: $r s=1-\left(\left(6^{*} 442\right) /\left(18^{\wedge} 3-18\right)\right)=0,544$

Hasil pengujian: Pada taraf signifikansi, $\alpha=0,01$ dan ukuran sampel $=18$, maka $\mathrm{rs}=0,544$ adalah $<$ dibandingkan $r_{\text {tabel }}=0,564 \rightarrow$ berarti : Terima Ho

Kesimpulan: hipotesis H0 adalah benar, yaitu "bertambahnya jumlah pelanggan telekomunikasi TIDAK mempunyai hubungan korelasional positif terhadap naiknya EBITDA para operator telekomunikasi”.

Dengan kata lain, berdasar dari analisis ini (belum menghitung aspek-aspek lain), disimpulkan bahwa liberalisasi pada bidang telekomunikasi terbukti TIDAK mempunyai korelasi positif terhadap kenaikan GDP negara kita.

Padahal kalau hanya sekilas, sejak dilaksanakan liberalisasi sector telekomunikasi, terdapat fakta bahwa jumlah pelanggan telekomunikasi dan EBITDA rata-rata operator telekomunikasi di Indonesia selalu meningkat dari tahun ke tahun seolah-olah proses liberalisasi telah mempunyai dampak positif bagi kemajuan perekonomian bangsa, tetapi setelah dianalisis lebih jauh, ternyata kenaikan jumlah pelanggan tidak berkorelasi dengan kenaikan EBITDA operator telekomunikasi, dimana disimpulkan bahwa kenaikan GDP 
sector telekomunikasi tidak berkorelasi dengan keberhasilan regulasi liberalisasi sector telekomunikasi.

\subsection{Problem \& Solution 2: Perhitungan Asosiasi Kausalitas}

Salah satu teknik untuk melakukan uji asosiasi kausalitas, atau hubungan sebab akibat adalah dengan menggunakan membuat tabulasi 2 × 2 lalu menghitung korelasi - kontijensi berupa koefisien phi, dimana nilai phi adalah antara -1 dan +1 , dan bila nilainya semakin mendekati +1 dan atau - 1 adalah berarti asosiasi - kausalitas sematerdapat hubungan yang semakin kuat.(tanda + menunjukkan asosiasi kausalitas positif dengan tanda - menunjukkan asosiasi kausalitas negatif).

Rumus menghitung Phi ada di bawah ini:

$$
p h i(f)=\left\{\frac{B \times C-A \times D}{\sqrt{(A+C)(B+D)(B+A)(D+C)}}\right\}
$$

Contoh: Kita diminta untuk menilai suatu hipotesis sebagai berikut: "Regulasi Interkoneksi yang berlaku sejak 1 januari 2007 berupa upaya menurunkan tariff retail, telah menyebabkan kenaikan jumlah pelanggan telekomunikasi, tetapi telah menyebabkan penurunan ARPU (Average Revenue per User) dari para operator”

Maka kita membuat tabulasi 2 × 2 sebagai berikut:

\begin{tabular}{|c|c|c|}
\hline & \multicolumn{2}{|c|}{$\begin{array}{l}\text { Jumlah pelanggan tahun } 2007 \text { adalah } \\
\text { naik dibandingkan } 2006\end{array}$} \\
\hline $\begin{array}{l}\text { ARPU tahun } 2007 \text { adalah } \\
\text { turun dibandingkan ARPU } \\
2006\end{array}$ & YA & TIDAK \\
\hline YA & B & A \\
\hline TIDAK & D & C \\
\hline
\end{tabular}

Data Yang Diketahui adalah sebagai berikut:

\begin{tabular}{|c|c|c|c|c|}
\hline \multirow[b]{2}{*}{ Penyelenggara } & \multicolumn{2}{|l|}{ Tahun 2006} & \multicolumn{2}{|l|}{ Tahun 2007} \\
\hline & Jumlah Pelanggan & $\begin{array}{l}\text { Revenue (Milyar } \\
\text { rup) }\end{array}$ & Jumlah Pelanggan & $\begin{array}{l}\text { Revenue (Milyar } \\
\text { rup) }\end{array}$ \\
\hline Telkom & 12885064 & 31716 & 15048000 & 37067 \\
\hline Indosat & 17090341 & 7051 & 25203835 & 8715 \\
\hline Bakrie & 1547557 & 291 & 3820701 & 545 \\
\hline Mobile 8 & 1825868 & 239 & 3012801 & 397 \\
\hline Telkomsel & 35597000 & 20737 & 47910000 & 25604 \\
\hline $\mathrm{XL}$ & 9527970 & 2554 & 15469000 & 3509 \\
\hline
\end{tabular}


Data diolah agar bisa menghitung nilai phi

\begin{tabular}{|l|r|r|r|r|}
\hline \multirow{2}{*}{ Penyelenggara } & Tahun 2006 & \multicolumn{1}{l}{ Tahun 2007} \\
& Jumlah Pelanggan & ARPU (Ribu rup) & Jumlah Pelanggan & ARPU (Ribu rup) \\
\hline Telkom & 12885064 & 2461 & 15048000 & 2463 \\
\hline Indosat & 17090341 & 413 & 25203835 & 346 \\
\hline Bakrie & 1547557 & 188 & 3820701 & 143 \\
\hline Mobile 8 & 1825868 & 131 & 3012801 & 132 \\
\hline Telkomsel & 35597000 & 583 & 47910000 & 534 \\
\hline XL & 9527970 & 268 & 15469000 & 227 \\
\hline
\end{tabular}

a) Perhitungan Uji Sebab Akibat pada soal ini:

I. B adalah sesuai dengan pernyataan sebagai berikut: "Jumlah pelanggan tahun 2007 adalah naik dibandingkan tahun 2006 DAN ARPU tahun 2007 adalah turun dibandingkan ARPU 2006. Maka dalam hal ini, variable B bernilai 4, karena ada 4 operator (Indosat, Bakrie, Telkomsel dan XL) yang memenuhi pernyataan tersebut.

II. A adalah sesuai dengan pernyataan sebagai berikut: "Jumlah pelanggan tahun 2007 adalah TIDAK naik dibandingkan tahun 2006 DAN ARPU tahun 2007 adalah turun dibandingkan ARPU 2006. Maka dalam hal ini, variable $\mathrm{A}=0$, karena tidak ada operator yang memenuhi pernyataan ini.

III. D adalah sesuai dengan pernyataan sebagai berikut: "Jumlah pelanggan tahun 2007 adalah naik dibandingkan tahun 2006 DAN ARPU tahun 2007 adalah TIDAK turun dibandingkan ARPU 2006. Maka dalam hal ini, variable D = 3, karena ada 3 operator Telkom, Mobile8 dan Bakri yang memenuhi pernyataan ini.

IV. C adalah sesuai dengan pernyataan sebagai berikut: "Jumlah pelanggan tahun 2007 adalah TIDAK naik dibandingkan 2006 DAN ARPU tahun 2007 adalah TIDAK turun dibandingkan ARPU 2006. Maka dalam hal ini, variable $\mathrm{C}=0$, karena tidak ada operator yang memenuhi pernyataan ini.

Didapat nilai phi $=0$, berarti kesimpulan Uji Asosiasi Kausalitas adalah "tidak ada hubungan sebab akibat antara kenaikan jumlah pelanggan telekomunikasi dengan penurunan ARPU dari operator telekomunikasi”.

\section{b) Perhitungan menggunakan uji perbedaan}

- Ada 4 operator yang mengalami kenaikan jumlah pelanggan, namun ARPU nya turun DIBANDINGKAN ada 2 operator yang mengalami kenaikan jumlah pelanggan 
namun ARPU naik. Kesimpulan "benar bahwa saat jumlah pelanggan telekomunikasi naik, terdapat penurunan ARPU operator telekomunikasi”.

\section{c) Kesimpulan}

- Dari Analisis Uji Asosiasi Kausalitas didapat: "tidak ada hubungan sebab akibat antara kenaikan jumlah pelanggan telekomunikasi dengan penurunan ARPU dari operator telekomunikasi”.

- Dari Analisis Uji Perbandingan: "benar bahwa saat jumlah pelanggan telekomunikasi naik, terdapat penurunan ARPU operator telekomunikasi”

- Kesimpulan akhir: Benar bahwa telah terjadi kenaikan jumlah pelanggan telekomunikasi yang diikuti oleh penurunan ARPU dari operator telekomunikasi, SETELAH adanya implementasi dari Regulasi Interkoneksi yang berlaku sejak 1 januari 2007, TETAPI hubungan antara kenaikan jumlah pelanggan dengan penurunan ARPU adalah BUKAN suatu hubungan SEBAB AKIBAT

\section{Metoda Baru untuk Menguji Tingkat Keadilan}

Untuk menguji apakah suatu kebijakan telah berjalan adil, maka pada bab ini ditawarkan untuk digunakan suatu metoda baru yang dikembangkan oleh Sigit Haryadi pada tahun 2017, yang disebut sebagai "Keadilan di atas Ketimpangan" (Fairness over Inequality), dimana penjelasan dari rumus dan teorinya silahkan disimak pada reference nomor [8], [9], [10], [11], dan [12]. Di bab ini hanya diberikan contoh perhitungan dengan menggunakan suatu "kalkulator internet" yang tersedia di: https://www.haryadi.org/fairness-over-inequality/

\subsection{Problem \& Solution 3: Perhitungan Tingkat Keadilan}

Misalkan terdapat lima operator seluler yang mendapat lisensi untuk beroperasi di suatu wilayah, dan terdapat data market dan bandwidth spectrum dari masing-masing operator sebagai berikut: (a) Data Market dalam triliun rupiah: operator $\mathrm{A}=80, \mathrm{~B}=35, \mathrm{C}=30$, operator $\mathrm{D}=20$ dan $\mathrm{E}=10$, (b) Data lisensi spectrum yang diberikan: operator $\mathrm{A}=150$ $\mathrm{MHz}, \mathrm{B}=70 \mathrm{MHz}, \mathrm{C}=60 \mathrm{MHz}, \mathrm{D}=40 \mathrm{MHz}$ dan $\mathrm{E}=30 \mathrm{MHz}$.

Soal: Hitunglah tingkat keadilan kebijakan lisenssi spectrum dari pemerintah

Jawab: Gunakan "kalkulator internet" yang ada di website https://www.haryadi.org/fairnessover-inequality/

Masukan Ukuran atau Banyak Grup dari variable $=5$.

Lalu masukan data market tiap operator pada kolom X (affected variable) dan data lisensi spectrum pada kolom Y (affecting variable). Lalu tekan "Calculate". Catatan: dalam hal ini 
yang sedang kita nilai adalah tingkat keadilan dari kebijakan pemerintah memberikan lisensi spektrum, maka lisensi tersebutlah yang menjadi variable Y.

Didapatkan indeks Keadilan di atas Ketimpangan $=0.82$ yang menunjukan bahwa kebijakan lisensi spectrum di negara tersebut adalah adil.

\section{Contoh Soal:}

1. Data suatu operator A selama 8 tahun terakhir sebagai berikut: th ke 1 trafik per pelanggan naik $10 \%$, ARPU naik $8 \%$, th ke 2 trafik per pelanggan naik $9 \%$, ARPU naik $7 \%$, th ke 3 trafik per pelanggan naik $6 \%$, ARPU naik $7,5 \%$, th ke 4 trafik per pelanggan naik $5 \%$, ARPU naik $4 \%$, th ke 5 trafik per pelanggan naik $3 \%$, ARPU naik $2 \%$, th ke 6 trafik per pelanggan naik $2,5 \%$, ARPU turun - $1 \%$, th ke 7 trafik per pelanggan turun - $1 \%$, ARPU naik $1 \%$, th ke 8 trafik per pelanggan turun $-2 \%$, ARPU turun $-1,5 \%$. Ujilah apakah untuk operator tersebut terdapat asosiasi korelasi dan asosiasi kausalitas untuk pernyaan berikut: "Jika trafik per pelanggan naik maka ARPU adalah turun

2. Data Market dalam triliun rupiah: operator $A=100, B=60, C=40$, operator $D=30$ dan $E$ $=10$, (b) Data lisensi spectrum yang diberikan: operator $\mathrm{A}=150 \mathrm{MHz}, \mathrm{B}=80 \mathrm{MHz}, \mathrm{C}=60$ $\mathrm{MHz}, \mathrm{D}=50 \mathrm{MHz}$ dan $\mathrm{E}=30 \mathrm{MHz}$. Soal: Hitunglah tingkat keadilan kebijakan lisenssi spectrum dari pemerintah

\section{DAFTAR PUSTAKA (REFERENCES)}

[1] Haryadi, Sigit. "Prinsip - Prinsip Penyusunan Kebijakan Negara Di Bidang Telekomunikasi.” Open Science Framework, 22 Jan. 2018. Web. https://osf.io/32g65/

[2] Haryadi, S. (2018, January 29). Bab 4 dari buku "Ekonomi Bisnis Regulasi dan Kebijakan Telekomunikasi”: Prinsip - Prinsip Ilmu Ekonomi \& Perbankan. Retrieved from https://osf.io/az9ye

[3] Haryadi, S. (2018, January 19). Catatan Kuliah Ekonomi, Bisnis, Regulasi dan Kebijakan Telekomunikasi Bab 2 semester 2 Tahun 2017/2018: Prinsip-Prinsip Ilmu Hukum. Retrieved from https://osf.io/3c9n4

[4] Haryadi, S. (2018, January 17). Bab 1. Tren Global Pada Bisnis \& Teknologi Telekomunikasi. Retrieved from https://osf.io/fvcha

[5] Haryadi, S. (2017, November). Probabilitas Statistik Untuk Insinyur. Retrieved from https://www.researchgate.net/publication/321183062_Probabilitas_Statistik_Untuk_In sinyur

[6] Haryadi, S. (2017). Internet Services Pricing Regulation. Retrieved from https://www.researchgate.net/publication/315683220 Internet Services and Pricing Regulat ion chapter 8 of the book Telecommunication\%27s Economy Business Regulation and Policy? iepl\%5Bviewld\%5D=nGfNTxUCgPAa6a8dL1uFd9Av\& iepl\%5BprofilePublicationlte $\underline{\mathrm{mVa}}$

[7] Haryadi, S. (2017). Ekonomi, Bisnis, Regulasi dan Kebijakan Telekomunikasi, Bab 6. Overview Organisasi Regulasi Telekomunikasi. Retrieved from https://www.researchgate.net/publication/314939825 Ekonomi Bisnis Regulasi dan Kebijak an Telekomunikasi Bab 6 Overview Organisasi Regulasi Telekomunikasi? iepl\%5Bviewl d\%5D=MYsKftgMFb5FVYwNZiMPP7Li\& iepl\%5BprofilePublicationltemVariant\%5D=default\& iep 
[8] Sigit Haryadi. (2017). The Fairness over Inequality Index: Unfairness is Disaster - a notebook of Sigit Haryadi. Researchgate. DOI: 10.13140/RG.2.2.34379.49449

[9] Sigit Haryadi. (2017). The Equality Correlation Method. Researchgate. DOI: 10.13140/RG.2.2.10443.80169

[10] Sigit Haryadi. (2017). Calculation of the Mobile Communication Competition using Haryadi Index. DOI: 10.13140/RG.2.2.15634.25280

[11] Sigit Haryadi. (2017). Haryadi Index and Its Applications in Science of Law, Sociology, Economics, Statistics, and Telecommunications. Penerbit Elex Media Komputindo. Jakarta. ISBN: 978-602-02-9895-5.

[12] Sigit Haryadi. (2017). Indeks Haryadi dan Penerapan di Ilmu Hukum, Sosiologi, Ekonomi, Statistik, dan Telekomunikasi. Penerbit Elex Media Komputindo, Jakarta. ISBN: 978-602-029896-2 